\title{
Long-Term Inhalation of Nitric Oxide for a Patient With Primary Pulmonary Hypertension
}

\author{
Eikan Koh, MD; Junko Niimura, MD; Tsuneyuki Nakamura, MD; \\ Hitoyoshi Yamakage, MD; Hiroaki Takahashi, MD
}

\begin{abstract}
Primary pulmonary hypertension is a disease with a high mortality rate and for which there is no satisfactory medical treatment. The safety of long-term inhalation of nitric oxide (NO) as a treatment is described. A 9-yearold girl inhaled NO for 32 weeks, accompanied with oral administration of beraprost sodium. Although NO did not improve her long-term prognosis, it eased the patient's dyspnea and increased her blood oxygenation. At doses of $20 \mathrm{ppm}$ or more, attempts to withdraw from inhaled $\mathrm{NO}$ seemed to lead to an immediate elevation of the pulmonary artery pressure. This rebound phenomenon did not happen at doses under $5 \mathrm{ppm}$. This case study suggests that long-term inhalation of $\mathrm{NO}$ is safe and effective, but that pulmonary hypertension may rebound following withdrawal at higher doses of NO. (Jpn Circ J 1998; 62: 940-942)
\end{abstract}

Key Words: Inhaled nitric oxide; Primary pulmonary hypertension; Rebound phenomenon

$\mathbf{P}$ rimary pulmonary hypertension $(\mathrm{PPH})$ is a disease characterized by the progressive elevation of both pulmonary artery pressure and resistance due to unknown etiology!,2 PPH has high mortality; the median survival time is less than 3 years after diagnosis $1,2 \mathrm{~A}$ variety of treatments of PPH have been used, including vasodilators, ${ }^{3,4}$ anticoagulant agents, 5 and lung or heart-lung transplantation6 However, except for transplantation, medical treatment has not improved the long-term prognosis. Recently, it has been reported that inhaled nitric oxide (NO) ${ }^{7-9}$ continuous intravenous prostacycline ${ }^{10,11}$ and living-related lobar transplantation ${ }^{12}$ have been effective. Inhaled NO acutely acts as a selective pulmonary vasodilator in the presence of pulmonary hypertension $(\mathrm{PH})$. However, the safety and effect of long-term inhaled NO is uncertain. We describe the effect, safety, and rebound phenomenon of the long-term use of inhaled NO. Our patient with PPH inhaled NO intermittently for 24 weeks and continuously for 8 weeks using a tight-fitting nasal mask with a noninvasive continuous positive airway pressure (CPAP).

\section{Case Report}

A 7-year-old girl visited the Department of Pediatrics following the detection of an abnormality in her ECG screening at her elementary school in August 1994. She had no symptoms and her physical findings were normal except for a mild accentuation of the second heart sound. Two-dimensional echocardiography showed a mildly dilated right ventricle with mild tricuspid regurgitation and moderate pulmonary hypertension with normal anatomical structure. In August 1995, she complained of dyspnea during exercise and Doppler echocardiography revealed a

(Received May 11, 1998; revised manuscript received September 2, 1998; accepted September 3, 1998)

Department of Pediatrics, Kanazawa Medical University, Ishikawa, Japan

Mailing address: Eikan Koh, Department of Pediatrics, Kanazawa Medical University, 1-1 Daigaku, Uchinada-machi, Kahoku-gun, Ishikawa 920-0293, Japan. E-mail: p-koh@ kanazawa-med.ac.jp markedly dilated right ventricle and an elevation of the pulmonary artery pressure, estimated from the magnitude of the tricuspid regurgitation. She was given beraprost sodium (BS), calcium-channel blocker, warfarin, and ambulatory oxygen. However, she deteriorated progressively and her status worsened from New York Heart Association (NYHA) functional class II to class III. In November 1996, the first cardiac catheterization revealed over-systemic pulmonary artery pressure with high pulmonary resistance (Table 1). The pulmonary artery pressure did not respond to beraprost sodium, so we decided to test inhaled NO. As it was difficult to place a catheter in the pulmonary artery, we used an echocardiographic monitor and found NO to be acutely effective at $20-40 \mathrm{ppm}$ (Table 2). We therefore decided to administer inhaled NO, with parental consent, as a bridge therapy to lobar lung transplantation.

The NO inhalation system, as described by Shibata et al ${ }^{13}$ had a modified circuit with a Servo ventilator (Siemens-Elema AB, Sweden). The NO gas was obtained from Nihon Sanso (Oyama, Japan) as a mixture of $800 \mathrm{ppm}$ in nitrogen. The inhaled $\mathrm{NO} / \mathrm{NO}_{2}$ concentration was continuously monitored by a NO/NO2 gas monitor (Saan, Japan). Initially, NO was supplied at $20 \mathrm{ppm}$ for $30 \mathrm{~min}$ everyday with a noninvasive nasal CPAP with GELTM Mask (Respironics Inc, PA, USA). Two months after starting the inhaled NO therapy, the second cardiac catheterization still revealed over-systemic pulmonary arterial pressure with a higher pulmonary resistance than that of the first cardiac catheterization (Table 1). At this time, the optimal concentration was rechecked and found to be still $20-40 \mathrm{ppm}$ (Table 2). Although the NO inhalation was continued for 30-60 min everyday, she deteriorated progressively to NYHA class IV.

Our search for a suitable living-related lobar transplant donor had not succeeded. In June, she complained of dyspnea with cyanosis at rest, requiring continuous NO inhalation. She could eat, drink, talk, and read a book while inhaling NO. Two weeks later, temporary removal of the nasal mask caused dyspnea and chest discomfort with desaturation though her methemoglobin levels were less 
Table 1 Cardiac Catheterization

\begin{tabular}{|c|c|c|c|c|}
\hline & \multicolumn{2}{|c|}{ 1st (19/11/96) } & \multicolumn{2}{|c|}{$2 n d(20 / 1 / 97)$} \\
\hline & Pressure (mmHg) (mean) & $\mathrm{SaO}_{2}$ & Pressure (mmHg) (mean) & $\mathrm{SaO}_{2}$ \\
\hline$R A$ & (24) & 32.5 & (26) & 37.1 \\
\hline$P A$ & $105 / 65(81)$ & 36.5 & 118/73 (90) & 34.9 \\
\hline$P C W$ & (12) & & (14) & \\
\hline$S A$ & $93 / 66$ (77) & 89.8 & $89 / 64$ (72) & 81.5 \\
\hline$C I\left(L \min ^{-1} m^{-2}\right)$ & 1.63 & & 1.38 & \\
\hline$R p\left(U \cdot m^{2}\right)$ & 43.1 & & 55.1 & \\
\hline
\end{tabular}

$\mathrm{SaO}_{2}$, arterial oxygen saturation; $\mathrm{RA}$, right atrium; $\mathrm{PA}$, pulmonary artery; $\mathrm{PCW}$, pulmonary capillary wedge; $\mathrm{SA}$, systemic artery; $C I$, cardiac index; Rp, pulmonary resistance.

Table 2 Testing of Nitric Oxide (NO) Inhalation

\begin{tabular}{|c|c|c|c|c|c|c|c|}
\hline & \multicolumn{7}{|c|}{ NO(ppm) } \\
\hline & pre & 5 & 10 & 20 & 30 & 40 & 80 \\
\hline \multicolumn{8}{|c|}{ Two-dimensional echocardiography (November 1996) } \\
\hline$H R(b p m)$ & 103 & 102 & 101 & 103 & 107 & 107 & \\
\hline $\mathrm{SpO}_{2}(\%)$ & 86 & 85 & 85 & 90 & 85 & 85 & \\
\hline$B p(m m H g)($ systole / diastole $)$ & $92 / 65$ & $87 / 55$ & $89 / 57$ & $87 / 56$ & $84 / 56$ & $84 / 54$ & \\
\hline$\% \operatorname{Met} H b(\%)$ & 0.6 & & & 1.6 & & 1.7 & \\
\hline$P G$ of $R V-R A$ by $C W(\mathrm{mmHg})$ & 68.9 & 69.6 & 64 & 67.2 & 65.6 & & \\
\hline \multicolumn{8}{|c|}{ During cardiac catheterization (January 1997) } \\
\hline$P A P(\mathrm{mmHg})$ & $123 / 75 /(90)$ & & $107 / 71 /(83)$ & $102 / 69 /(80)$ & & $103 / 67 /(79)$ & $111 / 69 /(83)$ \\
\hline$S A P(m m H g)$ & $84 / 62 /(73)$ & & $91 / 66 /(76)$ & $87 / 61 /(70)$ & & $91 / 65 /(74)$ & $93 / 64 /(73)$ \\
\hline PCWP (mmHg) (mean) & (12) & & (11) & (16) & & (18) & (11) \\
\hline$R A P(m m H g)($ mean $)$ & $(26)$ & & $(25)$ & (22) & & (22) & (24) \\
\hline$C I\left(\operatorname{Lmin}^{-1} \mathrm{~m}^{-2}\right)$ & 1.30 & & 1.30 & 1.34 & & 1.37 & 1.39 \\
\hline$R p\left(u \cdot m^{2}\right)$ & 60.0 & & 55.4 & 47.8 & & 44.5 & 51.8 \\
\hline $\mathrm{SaO}_{2}(\%)$ & 79.0 & & 85.2 & 84.0 & & 84.6 & 84.1 \\
\hline
\end{tabular}

$H R$, heart rate; $\mathrm{SpO}_{2}$, percutaneous oxgen saturation; $B p$, blood pressure; Met $H b$, methemogloblin; $P G$, pressure gradient, $R V$, right ventricle; RA, right atrium; $C W$, continuous wave doppler; PAP,pulmomary artery pressure; SAP, systemic artery pressure: $P C W$, pulmonary capillary wedge pressure; $\mathrm{CI}$, cardiac index; $\mathrm{Rp}$, pulmonary resistance; $\mathrm{SaO}_{2}$, arterial oxygen saturation.

than $1.0 \%$ throughout her clinical course. Rebound PH was regarded as a possibility 14 Lowering the NO to 5 ppm prevented these symptoms. One month later, she suddenly had severe chest pain, hypotension and severe cyanosis, requiring intubation and infusion of catecholamine. Unfortunately, the resuscitation was unsuccesful and she died. Postmortem revealed the right atrium, right ventricle and pulmonary artery to be dilated but with otherwise normal anatomical structure. Microscopic examination of the pulmonary vessels showed abnormal findings of $\mathrm{PPH}$ such as markedly narrow lumina with intimal fibrosis and medial hypertrophy, plexiform lesions, angiomatoid lesions and arteritis with fibrinoid necrosis ${ }^{15}$ There were no histological pulmonary findings that indicated chronic toxicity of the inhaled NO.

\section{Discussion}

A variety of vasodilaters have been used to treat $\mathrm{PPH}$. Recently, Barst et $\mathrm{al}^{11}$ and Shapiro et $\mathrm{al}^{16}$ have reported the long-term effects of continuous intravenous prostacycline for $\mathrm{PPH}$. As intravenous prostacycline could not be obtained in Japan, we used an oral analogue, BS. Though $\mathrm{BS}$ has been reported as effective against $\mathrm{PPH}$ and $\mathrm{PH}$ with congenital cardiac defect, ${ }^{17}$ with our patient it had no obvious effect either clinically or hemodynamically.

An alternative treatment is inhaled NO, which is reported to be an endothelium-derived relaxing factor ${ }^{18}$ It acts as a selective pulmonary vasodilator. Short-term usage of inhaled NO has been demonstrated in many clinical cases to be safe and effective for a variety of types of $\mathrm{PH}$, such as persistent $\mathrm{PH}$ of the neonate, ${ }^{19}$ residual $\mathrm{PH}$ after surgery of congenital cardiac defect ${ }^{20}$ and $\mathrm{PPH}^{7-9}$ As for the long-term usage of inhaled NO, however, its safety and effect is still uncertain. Of the few reports on long-term therapy in patients with PPH, an adult patient was administered inhaled NO for 36 weeks without adverse effects? To our knowledge, our case is the first report of a child being administered inhaled NO for as long as 32 weeks. The use of a nasal mask with CPAP in NO therapy proved to be a practical way of managing a conscious child patient. Similar to several previous observations, our data showed that inhaled NO is safe and effective, though it did not lead to the improvement of her long-term prognosis. Her downhill clinical course eventually required continuous inhalation of NO, which was successfully delivered by the nasal mask. However, temporary removal of the nasal mask and withdrawal of NO caused an abrupt clinical deterioration. Other investigators have also noted abrupt changes in the clinical status and hemodynamics during temporary cessation?1,22 Miller et al has demonstrated hemodynamically the rebound $\mathrm{PH}^{14}$ Unfortunately, our hemodynamic data were unavailable because of the patient's serious state and her parents' refusal. The mechanism of rebound $\mathrm{PH}$ is unknown, but may be related to downregulation of endogenous NO production or decreased NO sensitivity during NO administration. The rebound signs may be a frequent and potentially dangerous complication of drug withdrawal, perhaps a consequence of long-term use of inhaled NO. In the present case, the rebound signs after withdrawal 
of NO could be relinquished by a continuous low dose of inhaled NO $(<5 \mathrm{ppm})$. Radermacher et $\mathrm{al}^{23}$ have also found a lower dose of inhaled NO to be clinically effective, even though hemodynamic NO testing showed the optimal concentration to be $20-40 \mathrm{ppm}$. Taking into consideration not only the hazards of methemoglobinemia and $\mathrm{NO}_{2}$ production but also rebound $\mathrm{PH}$, the lower dose of inhaled NO $(<5 \mathrm{ppm})$ might be safe for long-term use.

\section{References}

1. Rich S, Dantzker DR, Ayres SM, Begofsky EH, Brundage BH, Detre KM, et al: Primary plumonary hypertension: A national prospective study. Ann Intern Med 1987; 107: 216-223

2. D’Alonzo GE, Barst RJ, Ayres SM, Bergofsky EH, Brundage BH, Detre KM, et al: Survival in patients with primary pulmonary hypertension: Results from a national prospective registry. Ann Intern Med 1991; 115: 343 - 349

3. Barst RJ: Pharmacologically induced pulmonary vasodilatation in children and young adults with primary pulmonary hypertension. Chest 1986; 89: 497-503

4. Rich S, Kaufmann E, Levy PS: The effect of high doses of calciumchannel blockers on survival in primary pulmonary hypertension. $N$ Engl J Med 1992; 327: 76-81

5. Fuster V, Steele PM, Edwards WD, Gersh BJ, McGoon MD, Frye RL: Primary pulmonary hypertension: natural history and the importance of thrombosis. Circulation 1984; 70: 580-587

6. Pasque MK, Trulock EP, Cooper JD, Triantafilou AN, Huddelston $\mathrm{CB}$, Rosenbloom M, et al: Single lung transplantation for pulmonary hypertension. Circulation 1995; 92: 2252-2258

7. Snell GI, Salmonsen RF, Bergin P, Esmore DS, Khan S, Williams TJ: Inhaled nitric oxide used as a bridge to heart-lung transplantation in a patient with end-stage pulmonary hypertension. Am J Respir Crit Care Med 1995; 151: $1263-1266$

8. Channick RN, Newhart JW, Johnson FW, Williams PJ, Auger WR, Fedullo PF, et al: Pulsed delivery of inhaled nitric oxide to patients with primary pulmonary hypertension: An ambulatory delivery system and initial clinical tests. Chest 1996; 109: 1545-1549

9. Cockrill BA: The use of nitric oxide in primary pulmonary hypertension. Respir Care Clin N Am 1997; 3: 505-519

10. Higenbottam TW, Wheeldon D, Wells FC, Wallwork J: Long-term treatment of primary pulmonary hypertension with continuous intra- venous epoprostenol (prostacycline), Lancet 1984; I: 1046-1047

11. Barst RJ, Rubin LJ, Long WA, McGoon MD, Rich S, Badesch DB, et al: A comparison of continuous intravenous epoprostenol (prostacycline) with conventional treatment for primary pulmonary hypertension. N Engl J Med 1996; 334: 296-301

12. Stanes VA, Barr ML, Cohen RG, Hagen JA, Weiis WJ, Horn MV, et al: Living-donor lobar lung transplantation experience: Intermediate results. J Thorac Cardiovasc Surg 1996; 112: 1284-1291

13. Shibata Y, Okamoto K, Sato T, Kukita I, Kikuta K: The safety of a nitric oxide inhalation system using a conventional infant respirator. Acta Paediatr Jpn 1996; 38: 143-146

14. Miller OI, Tang SF, Keech A, Celermajer DS: Rebound pulmonary hypertension on withdrawal from inhaled nitric oxide. Lancet 1996; 346: $51-52$

15. Wagenvoort CA, Wagenvoort N: Primary pulmonary hypertension: a pathologic study of the lung vessels in 156 clinically diagnosed cases. Circulation 1970; 42: $1163-1184$

16. Shapiro SM, Oudiz RJ, Cao T, Romano MA, Beckmann XJ, Georgiou D, et al: Primary pulmonary hytertension: Improved longterm effets and survival with continuous intravenous epoprostenol infusion. J Am Coll Cardiol 1997; 30: 343-349

17. Saji T, Ozawa Y, Nakayama T, Matuura H, Hashiguchi R, Matsuo N, et al: Short- and long-term effects of the new oral prostacyclin analogue, beraprost sodium, in patients with severe pulmonary hypertension. J Cardiol 1996; 27: 197-207

18. Palmer RMJ, Forrige AG, Moncada S: Nitric oxide release accounts for the biological activity of endothelium-derived relaxing factor. Nature 1987; 327: 524-526

19. Geggel RL: Inhalational nitric oxide: a selective pulmonary vasodilator for treatment of persistent pulmonary hypertension of the newborn. J Pediatr 1993; 123: 76-79

20. Wessel DL: Inhaled nitric oxide for the treatment of pulmonary hypertension before and after cardiopulmonary bypass. Crit Care Med 1993; 21: S344-S345

21. Girard C, Durand DG, Vedrinne C, Pannetier JC, Estanove S, Falke $\mathrm{K}$, et al: Inhaled nitric oxide use postcardiac transplantation. $J$ Cardiothorac Vasc Anesth 1993; 7: 481 -485

22. Watkins DN, Jenkins IR, Rankin JM, Clarke GM: Inhaled nitric oxide in severe acute respiratory failure: Its use in an intensive care unit and description of delivery system. Anesth Intensive Care 1993; 21: $861-866$

23. Radermacher P, Rammos S: Low dose inhaled nitric oxide causing selective pulmonary vasodilation in a child with idiopathic pulmonary hypertension. Eur J Pediatr 1994; 153: 691-693 